\title{
Effects of Pore Geometry and Pore Structure on Dry P-Wave Velocity
}

\author{
Suryo Prakoso ${ }^{1}$, Pudji Permadi ${ }^{1} \&$ Sonny Winardhie ${ }^{2}$ \\ ${ }^{1}$ Petroleum Engineering, Faculty of Mining and Petroleum Engineering, Institut Teknologi Bandung, Indonesia \\ ${ }^{2}$ Geophysical Engineering, Faculty of Mining and Petroleum Engineering, Institut Teknologi Bandung, \\ Indonesia \\ Correspondence: Suryo Prakoso, Petroleum Engineering, Faculty of Mining and Petroleum Engineering, Institut \\ Teknologi Bandung, Indonesia. Tel: 628-129-501-701. E-mail: suryo1prakoso@yahoo.com
}

Received: March 23, 2016

Accepted: April 4, 2016

Online Published: June 15, 2016

doi:10.5539/mas.v10n8p117

URL: http://dx.doi.org/10.5539/mas.v10n8p117

\begin{abstract}
The behavior of compressional or P-wave velocity passing through natural porous rocks with heterogeneous and irregular shapes of the pore system is not well understood. The present study implemented a modified Kozeny equation to characterize pore attributes, pore geometry and structure, in an attempt to investigate factors influencing the velocity. This equation is in the form of a power law one from which a concept of similarity in pore attributes can be derived. Employing a large number of data of porous sandstones, the results show that a similarity in the pore attribute plays an important role in relating the velocity with the details of geometry and structure of the pores system. For a given group of rocks having similar pore structure, an increase in the pore geometry variable, $(k / \phi)^{0.5}$, tends to increase the velocity provided that the increase in the geometry is due to an increase in permeability followed by a decrease in porosity. Overall, the prediction of P-wave velocity is best obtained when the rocks are grouped according to pore structure similarity.
\end{abstract}

Keywords: P-wave velocity, pore geometry, pore structure, tortuosity, internal specific surface area

\section{Introduction}

The main problem of defining the relation of wave velocity of porous rocks with petrophysical properties is that the heterogeneities of rocks are closely associated with the geological processes that formed the rocks. Variations in the geological processes associated with the deposition and diagenetic process control the rock texture (grain size, uniformity of grain size and grain arrangement), the type of minerals, and clay content which in turn affects the size, shape and relationships or connectivity between the pores. Types, content, shape, and composition of the material produce different grain distributions so that the geometry and pore structure are also different. The complexity of the pore geometry and pore structure will influence the velocity variations in wave propagation.

Many investigators have specifically identified the detailed characteristics of the solid part and the pores of sandstones that influence on wave velocity. One of them (Han et al., 1986), found that the most important parameters that affect wave velocity in shaly sandstones are porosity and clay content. Later, Nur et al. (1995) defined so called critical porosity for which a given class of porous material will lose its inter-grain contacts. The value of critical porosity of a porous rock is determined by its common mineralogy, grain sorting and angularity, and subsequent diagenetic processes after deposition (Mavko et al., 2009). The use of knowing the critical velocity of a group of rocks is to obtain a better relation between the wave velocity and porosity.

Other investigators looked at more specific characteristics of pore systems that could control the behavior of wave velocity. Prasad (2002) showed that wave velocity was better correlated with permeability when the rocks employed were grouped on the basis of hydraulic unit representing similarity in pore geometry. Fabricius et al. $(2007,2010)$ and Mokhtar et al. (2010) found that depositional texture controlling the petrophysical properties determined also wave velocity of the rocks. Also, Weger and Eberli (2009), Xu and Payne (2009), Verwer et al. (2010), Rahman and Pierson (2011) and Bashah and Pierson (2012) were able to quantify the pore geometry by pore-type variations and parameters of pore space that is expressed by domsize, roundness $(\gamma)$, aspect ratio (AR), and pore network complexity or Perimeter over area (POA) obtained from petrographic analysis. It is then revealed that the complexity of pores is one of the main factors that influence P-wave velocity.

This paper presents a different but simpler approach to quantifying pore geometry and pore structure of porous rocks. It is believed that petrophysical properties such as porosity and permeability integrated with microscopic 
geological data can carry information about the complexity of pore geometry and structure. Therefore, the behavior of wave velocity of porous rocks can be recognized by only measuring porosity, permeability, and wave velocity on the rocks in the attempt to study the effects of pore attributes on the wave velocity. The main objective of this study is to investigate the responses of acoustic wave velocity with the changes of pore geometry for porous rocks having similar pore structure and the changes of pore structure for those of similar pore geometry. The present study focuses on dry P-wave velocity measured on sandstone core plugs of various both pore geometries and pore structures.

\section{Method and Data}

\subsection{Pore Geometry and Pore Structure}

Permadi and Susilo (2009) and Wibowo and Permadi (2013) developed an approach for rock grouping based on the relationship between pore geometry and pore structure. Pore geometry here is simply an equivalent to mean hydraulic radius (Harmsen, 1955) and pore structure is a pore attribute that is influenced by pore shape, pore tortuosity, and internal surface area which all make up the architecture of pores system. These all are combined and desribed in an equation introduced by Kozeny (1927). His widely known equation can be re-written in two forms as follows (Permadi and Susilo, 2009 and Wibowo and Permadi, 2013):

$$
\left(\frac{k}{\phi}\right)^{0.5}=\phi\left(\frac{1}{\left(F_{s} \tau S_{b}^{2}\right.}\right)^{0.5}
$$

and

$$
\left(k / \phi^{3}\right)=1 /\left(F_{s} \tau s_{b}^{2}\right)
$$

Thus, replacing the variable $1 /\left(F_{s} \tau S_{b}^{2}\right)$ in Eq. (1) with $\left(k / \phi^{3}\right)$ and taking $\phi$ outside the bracket in the right hand side of Eq. (1) as a constant $\phi^{\prime}$ yields the following equation:

$$
(k / \phi)^{0.5}=\phi^{\prime}\left(k / \phi^{3}\right)^{0.5}
$$

where $k$ is permeability, $\phi$ is porosity and $\phi^{\prime}$ is a constant as described in Eq. (4) below, $F_{s}$ is shape factor, $\tau$ is tortuosity, and $S_{b}$ is specific internal surface area with reference to bulk volume. The variable $(k / \phi)^{0.5}$ is so called as pore geometry variable and $\left(k / \phi^{3}\right)$ is pore structure variable. Plotting $(k / \phi)^{0.5}$ as dependent variable against $\left(k / \phi^{3}\right)$ as the independent variable would yield a straight line with a positive slope, 0.5 according to Eq. (3). It should be recalled that the Kozeny equation was originally developed by considering a porous medium as a bundle of smooth tortuos capillaric tubes. Harmsen (1955) then defined the term mean hydraulic radius for $(k / \phi)^{0.5}$ which was previously used by Leverett (1940) to normalize capillary pressure curves.

Treating the rocks as a part of the nature that obeys the power law behavior, Equation (3) may be written in a more general form, a power law equation:

$$
\left(\frac{k}{\phi}\right)^{0.5}=a\left(\frac{k}{\phi^{3}}\right)^{b} \text { or } \quad\left(\frac{k}{\phi}\right)^{0.5}=a\left(\frac{1}{\left(F_{s} \tau \Sigma_{b}^{2}\right.}\right)^{b}
$$

where $a$, which was $\phi^{\prime}$ in Eq. (3) above, is a constant that is interpreted as a correction factor for volumetric fluid flow efficiency for irregular pore systems (Permadi and Wibowo, 2013) and $b$ is the power law exponent, an indicator of the complexity of pore structure. The maximum value of $b$ is 0.5 for smooth capillaric systems as described above. For natural porous rocks having similar microscopic geological features, it was shown that the value of $b$ is less than 0.5 . The lower $b$ value, the more complex the pore structure.

\subsection{Data and Wave Velocity Measurement}

Two data sets of sandstone samples used in this study include routine core analysis consisting of permeability, porosity, lithology description, special core analysis data, and sedimentology analysis data such as petrographic (thin section) and XRD data. Wave velocity data were obtained from laboratory measurements on the rock samples by using SonicViewer-SX equipped with pizoelectric transducers to measure the P-waves and S-waves velocity.

The cores for data set 1 were obtained from the North West Java Basin. As many as 215 core plugs with a diameter of 1 inch and the length ranging from 1.2 to 5.4 centimeters are available for use. The sandstone obtained from Talangakar Formation, aged Lower Oligocene (Syn-rift II) until the Upper Oligocene (Post-rift) 
was deposited on the deltaic-transition zone environment. Talangakar Formation is dominated by fine to coarse grained sandstone interspersed with shale, siltstone, coal and limestone. All samples are dominantly composed of mineral quarzt. The porosity ranges from 5.6 to $39.31 \%$, while the permeability is between 0.04 and $5,153 \mathrm{mD}$, and the grain density ranges from 1.84 to $2.90 \mathrm{gr} / \mathrm{cc}$.

The sandstone samples for data set 2 were originated from the Kutai Basin. As many as 430 core plugs with a diameter of 1 inch and the length ranging from 1.6 to 6.5 centimeters were provided for this study. The sandstone obtained from Balikpapan Formation, aged Middle Miocene until Late Miocene was deposited on the deltaic plain-deltaic front environment. Balikpapan Formation is dominated by fine to coarse grained sandstone interspersed with claystone, shale, and coal. All samples are composed of the dominant mineral quartz. The porosity ranges from 4.5 to $36.9 \%$, while the permeability is between 0.05 and $5504 \mathrm{mD}$, and the grain density ranges from 1.91 to $3.34 \mathrm{gr} / \mathrm{cc}$.

Wave velocity measurements on the 645 core samples were measured in the laboratory on dry conditions, at atmospheric pressure $(1 \mathrm{~atm}$ or $0.101 \mathrm{Mpa})$ and room temperature $\left(25^{\circ} \mathrm{C}\right)$. Before measurements, the core samples were dried at $150{ }^{\circ} \mathrm{F}$ for 12 hours. Acoustic wave velocity was measured using SonicViewer-Sx (see Figure 1), which is equipped with two pairs of pizoelectric transducer to measure the P-wave velocity $\left(V_{p}\right)$ and S-wave velocity $\left(V_{s}\right)$. The results of P-wave velocity $\left(V_{p}\right)$ measurements have a range of values between 1146 and $4339 \mathrm{~m} / \mathrm{s}$, while the S-wave velocity $\left(V_{s}\right)$ measurements ranges from 798 to $2714 \mathrm{~m} / \mathrm{s}$.

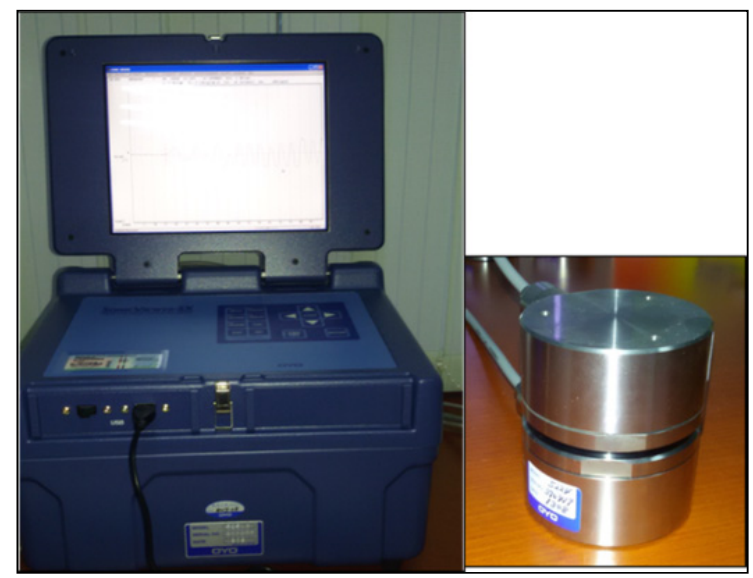

Figure 1. The equipment for ultrasonic measurement

P-wave velocity was measured by sending signals from the P-wave transducer on one side of the core sample and the P-wave signal was recorded by the transducer on the other side of the core samples. Velocity was obtained by dividing the measured transit time of the recorded signal with the length of the core sample. S-wave velocity was measured in the same manner using S-wave transducer (see Figure 2).

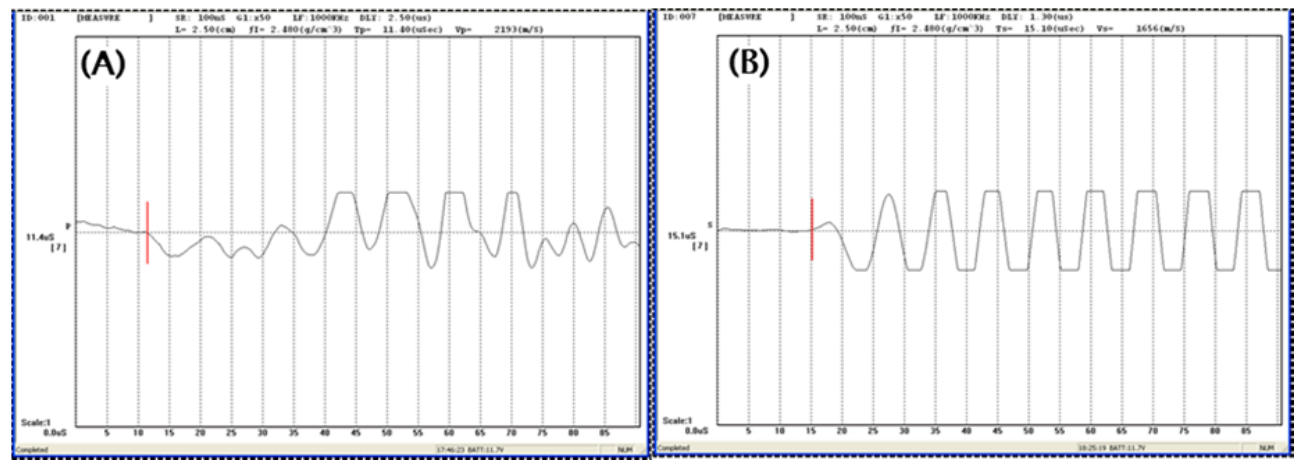

Figure 2. Results of measurement P-waves velocity (A) and S-wave velocity (B)

Calibration to the equipment used here was always made before and after measurements of $\mathrm{P}$ and $\mathrm{S}$-wave of 
velocity on the core samples by employing standard core samples of Berea Sandstone. At the very begining of the experiment, calibration was carried out to ascertain the consistency of the equipment in measuring $\mathrm{P}$ and S-wave velocity so that any anomaly caused by the equipment during the course of measurements can be detected earlier. Figure 3 shows the results of calibration that indicate a good consistency with a standard deviation for P-wave and S-wave velocity is $32 \mathrm{~m} / \mathrm{s}$ and $11.8 \mathrm{~m} / \mathrm{s}$, respectively.

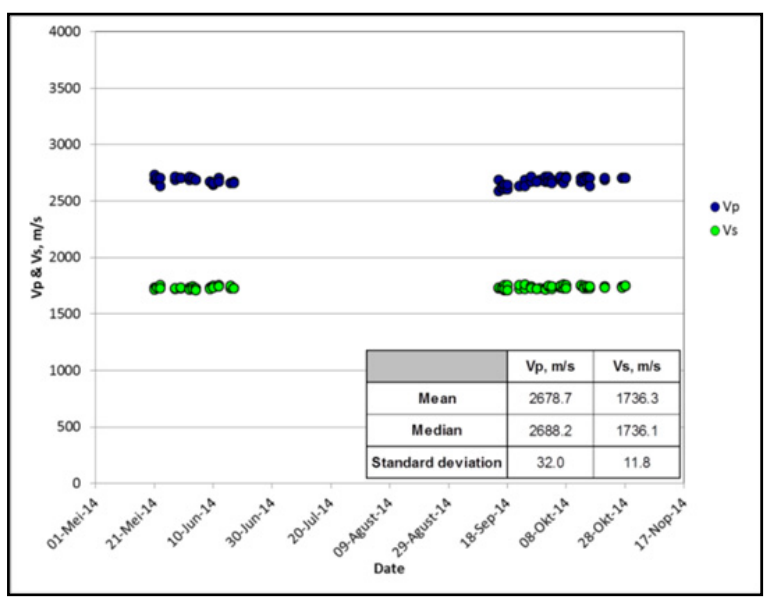

Figure 3. Mean, median and standard deviation results of measurement P-waves velocity and S-wave velocity of Berea Sandstone

\section{Results and Discussion}

\subsection{Rock Grouping Based on Microscopic Geological Features}

According to Eq. (4), pore geometry variable $(k / \phi)^{0.5}$ and pore structure variable $\left(k / \phi^{3}\right)$ were determined by employing the data of routine core analysis of all the core samples. Rocks grouping were conveniently performed by applying the rock type chart published by Wibowo and Permadi (2013). The results are shown in Figures 4 and 5, respectively, for sandstone data set 1 and sandstone data set 2 . As can be seen in these figures, all the data points of each data set cover eleven rock type lines. All the data points falling on and closer to a line are grouped to be a distinguished rock type that is differentiated from the other groups. This is the basis for sorting all the rock samples to establish the rock groups or the so called rock types for further analysis. Referring to these figures, it should be noted that the larger the rock type number the lower the slope of the line, the more complex the pore structure, resulting in poorer quality of the rock type. The regression equations for each group are shown in Table 1.

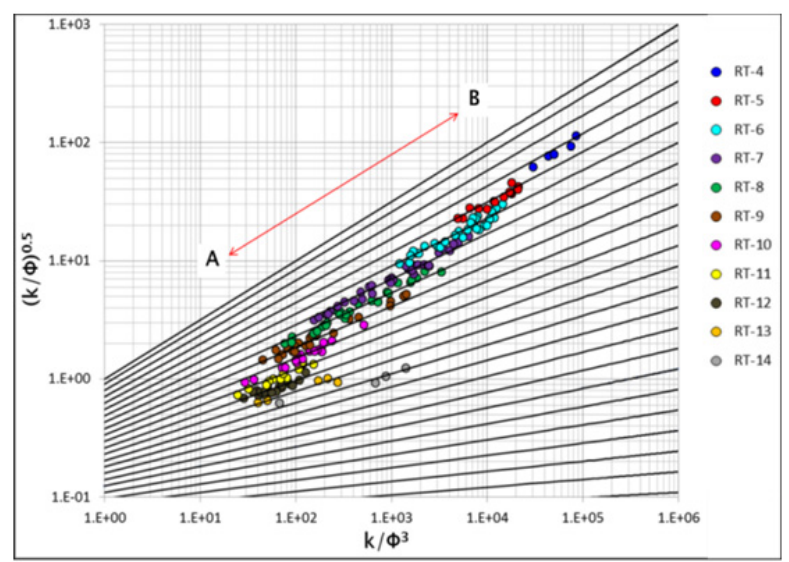

Figure 4. Identification of the rock type based on pore geometry and pore structure for data set 1

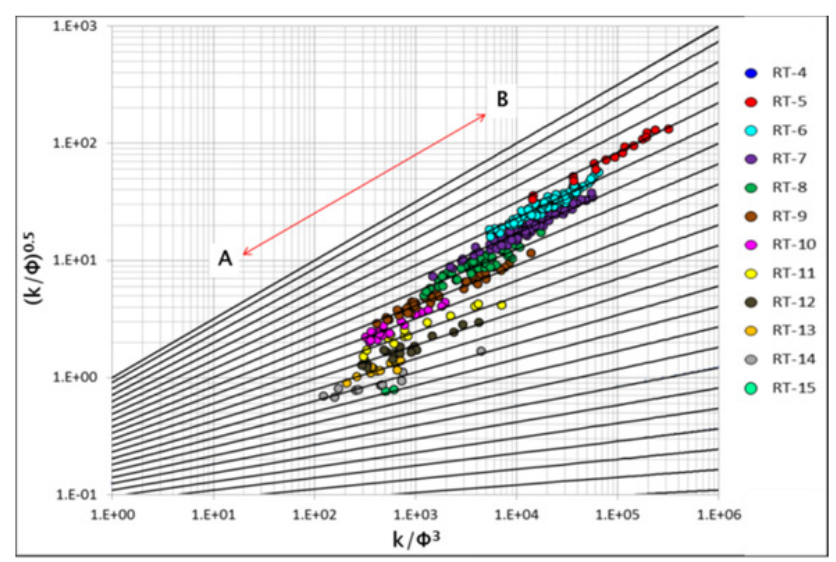

Figure 5. Identification of the rock type based on pore geometry and pore structure for data set 2 
Table 1. Regression equations of each rock type for data set 1 and 2

\begin{tabular}{ccc}
\hline \multirow{2}{*}{ RT } & \multicolumn{2}{c}{ Regression equations } \\
\cline { 2 - 3 } 4 & $(k / \phi)^{0.5}=0.6933\left(k / \phi^{3}\right)^{0.4406}$ & Data Set 2 \\
5 & $(k / \phi)^{0.5}=0.6199\left(k / \phi^{3}\right)^{0.422}$ & - \\
6 & $(k / \phi)^{0.5}=0.5473\left(k / \phi^{3}\right)^{0.405}$ & $(k / \phi)^{0.5}=0.6119\left(k / \phi^{3}\right)^{0.4251}$ \\
7 & $(k / \phi)^{0.5}=0.4676\left(k / \phi^{3}\right)^{0.3904}$ & $(k / \phi)^{0.5}=0.5279\left(k / \phi^{3}\right)^{0.4082}$ \\
8 & $(k / \phi)^{0.5}=0.4188\left(k / \phi^{3}\right)^{0.3705}$ & $(k / \phi)^{0.5}=0.4317\left(k / \phi^{3}\right)^{0.3681}$ \\
9 & $(k / \phi)^{0.5}=0.378\left(k / \phi^{3}\right)^{0.352}$ & $(k / \phi)^{0.5}=0.3699\left(k / \phi^{3}\right)^{0.3524}$ \\
10 & $(k / \phi)^{0.5}=0.3291\left(k / \phi^{3}\right)^{0.3277}$ & $(k / \phi)^{0.5}=0.3333\left(k / \phi^{3}\right)^{0.3284}$ \\
11 & $(k / \phi)^{0.5}=0.291\left(k / \phi^{3}\right)^{0.3043}$ & $(k / \phi)^{0.5}=0.3002\left(k / \phi^{3}\right)^{0.3082}$ \\
12 & $(k / \phi)^{0.5}=0.2622\left(k / \phi^{3}\right)^{0.2831}$ & $(k / \phi)^{0.5}=0.2596\left(k / \phi^{3}\right)^{0.2859}$ \\
13 & $(k / \phi)^{0.5}=0.2344\left(k / \phi^{3}\right)^{0.2649}$ & $(k / \phi)^{0.5}=0.2345\left(k / \phi^{3}\right)^{0.2665}$ \\
14 & $(k / \phi)^{0.5}=0.2065\left(k / \phi^{3}\right)^{0.2428}$ & $(k / \phi)^{0.5}=0.2051\left(k / \phi^{3}\right)^{0.2439}$ \\
15 & - & $(k / \phi)^{0.5}=0.1847\left(k / \phi^{3}\right)^{0.2272}$ \\
\hline
\end{tabular}

The use of available petrographic analysis data was to identify the relationship between microscopic geological features and the rock types established. The analysis to relate the P-wave velocity data with the pore geometry and pore structure, as well as with the geological components, was than made.

After grouping all the rock samples for each data set, identification of each rock type based on the microscopic geological features was carried out. The results are exhibited in Tables 2 and 3, the second column, indicating that the dominant influence on rock typing of the sandstones is rock texture which includes grain size, sorting, angularity and grain roundness. The images shown in last column of the tables may help in identifying typical the grains size of each rock type. In particular, among the first three rock types of each data set, the differences in the grain size are clearly observed. The rock types having very good to excellent permeability and porosity are those composed of larger grains size and dominated by quartz with kaolinite as the main cementing material. These rock types have members with relatively large pore geometry or high mean hydraulic radii and simpler pore structures. Other factors that determine the rock samples in the position of rock typing are the results of diagenetic processes. The presence of illite minerals and some other minerals such as chorite, phyrite and calcite tend to degrade the quality of the rocks. Having such mineral contents, the complexity of pore structure of the rocks usually gets higher. The rock samples located in even lower quality rock types are those with grains being cemented by calcite and dolomite, causing the increases of rock hardness. 
Table 2. Microscopic characteristics each rock type for data set 1

\begin{tabular}{|c|c|c|c|c|c|c|c|c|}
\hline \multirow{2}{*}{ RT } & \multirow{2}{*}{ MICROSCOPIC GEOLOGICAL FEATURE } & \multicolumn{2}{|c|}{$k(m D)$} & \multicolumn{2}{|c|}{$\phi(\%)$} & \multicolumn{2}{|c|}{ Vp dry $(\mathrm{m} / \mathrm{s})$} & \multirow{2}{*}{ PETROGRAPHY IMAGE } \\
\hline & & Min & Max & Min & Max & Min & Max & \\
\hline RT-4 & $\begin{array}{l}\text { Sd; med hd, mg, mod srtd, sbang-sbrnd, I>pn, } \\
\text { qtz, less pot \& plag Felds, tr calc-dol-sid, tr mica, } \\
\text { sli glauc, sli arg, qtz-kao cement }\end{array}$ & 1406 & 5153 & 35.6 & 39.3 & 1146 & 1527 & $\mathrm{k}=2191 \mathrm{mD}, \varphi=36.9 \%, \mathrm{Vp}$ dry $=1527 \mathrm{~m} / \mathrm{s}^{2}$ \\
\hline RT-5 & $\begin{array}{l}\text { Sd; med hd, fg, mod-w srtd, sbang-sbrnd, } \\
\text { l>pn/cc>pl, qtz-chert, less pot \& plag felds, tr } \\
\text { calc, Vrf, pxline-qtz, sli mica, sli glauc, sli arg, qtz- } \\
\text { kao-ill-chlor-pyrt cement }\end{array}$ & 168 & 706 & 27.3 & 34.6 & 1219 & 2063 & ${ }_{\mathrm{k}=428 \mathrm{mD}, \varphi=29.26 \%, \mathrm{Vpdry}=1552 \mathrm{~m} / \mathrm{s}}$ \\
\hline RT-6 & $\begin{array}{l}\text { Sd; med hd-hd, fg, mod-w srtd, sbang-sb rnd, } \\
\text { cc>pl, qtz-chert, less pot \& plag Felds, sli calc, } \\
\text { vrf, phyllite, pxline-qtz, sli mica, Heavy minerals, } \\
\text { sli glauc, sli arg, qtz-kao-ill-chor-pyrt-calc cement }\end{array}$ & 24 & 224 & 20.1 & 29.5 & 1461 & 3304 & 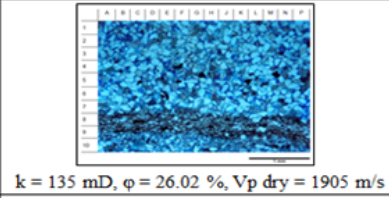 \\
\hline RT-7 & $\begin{array}{l}\text { Sd; med hd-hd, vf/fg, mod-w srtd, sbang-sbrnd, } \\
\text { pn>pl>cc>l, qtz-chert, less pot \& plag Felds, sli } \\
\text { calc, pxline-qtz, sli mica, Heavy minerals, sli } \\
\text { glauc, sli arg, qtz-sid-calc, kao-ill-pyrt-glauc } \\
\text { cement }\end{array}$ & 2.5 & 52 & 18.2 & 25.3 & 1642 & 3137 & 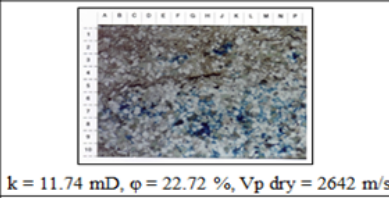 \\
\hline RT-8 & $\begin{array}{l}\text { Sd; med hd-hd, vf-fg, mod-w srtd, sbang-sb rnd, } \\
\text { pn>pl>cc, qtz-chert, less pot \& plag Felds, sli } \\
\text { calc, pxline-qtz, sli mica, Heavy minerals, sli } \\
\text { glauc, sli arg, qtz-sid-calc-kao-ill-pyrt cement }\end{array}$ & 0.8 & 11.5 & 14 & 23.6 & 1836 & 3143 & 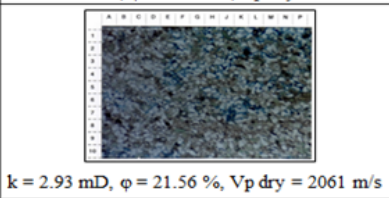 \\
\hline RT-9 & $\begin{array}{l}\text { Sd; med hd-hd, vf-fg, mod-w srtd, sbang-sbrnd, } \\
\text { cc> long, qtz-chert, less pot \& plag Felds, sli calc, } \\
\text { pxline-qtz, sli mica, Heavy minerals, sli glauc, } \\
\text { slightly arg, qtz-cal-kao-ill-pyrt-chlo cement }\end{array}$ & 0.4 & 3.7 & 13.4 & 21.6 & 1979 & 3333 & 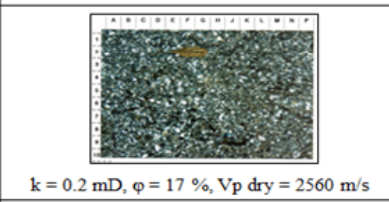 \\
\hline RT-10 & $\begin{array}{l}\text { Sd; hd, vf-fg, p-mod srtd, sbang-subrnd, qtz- } \\
\text { chert, less pot \& plagFelds, sli calcite, sli mica,sli } \\
\text { glauc, sli arg, qtz-calc-clay cement }\end{array}$ & 0.15 & 1.05 & 12.5 & 17.2 & 2128 & 3200 & No data \\
\hline RT-11 & $\begin{array}{l}\text { Sd; hd, vf-fg, p-mod srtd, sbang-sbrnd, cc > pl, } \\
\text { qtz-chert, less pot \& plag Felds, sli calc, pxline- } \\
\text { qtz, sli mica, sli arg, side-pyrt-clay cement }\end{array}$ & 0.08 & 0.25 & 10.8 & 14.8 & 2878 & 3600 & No data \\
\hline RT-12 & $\begin{array}{l}\text { Sandy-silstone; med hd-hd, vf gr, p-mod srtd, } \\
\text { sbang-sb rnd, plr>pn>FI, qtz, less plag Felds, sli } \\
\text { calc, pxline-qtz, sli mica, sli heavy mineral, sli } \\
\text { glauc, sli arg, kao-pyrt-calc cement }\end{array}$ & 0.06 & 0.13 & 9.13 & 13.7 & 2315 & 3571 & 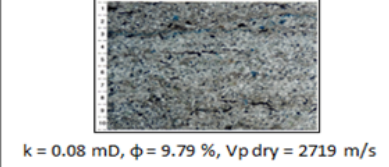 \\
\hline RT-13 & $\begin{array}{l}\text { Sd Calc Cemented; hd-vhd, vf-fg, p-mod srtd, } \\
\text { sbang-sb rnd, fl>pl>l, qtz, less pot \& plag Felds, } \\
\text { sli calc, sli glauc, sli arg, calc cemented }\end{array}$ & 0.04 & 0.07 & 5.67 & 10 & 2817 & 3306 & 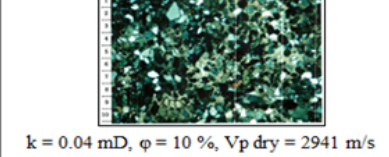 \\
\hline RT-14 & $\begin{array}{l}\text { Sd Calcite Cemented; hd-vhd, vfg, w srtd, sbang- } \\
\text { sbrnd, fl>pl>l, qtz, less pot \& plag Felds, sli calc- } \\
\text { dol, sli pxline qtz, sli mica, sli heavy mineral, tr } \\
\text { glauc, sli arg, calc-dol cemented }\end{array}$ & 0.03 & 0.05 & 3.28 & 3.58 & 3824 & 4368 & No data \\
\hline
\end{tabular}


Table 3. Microscopic characteristics each rock type for data set 2

\begin{tabular}{|c|c|c|c|c|c|c|c|c|}
\hline \multirow{2}{*}{ RT } & \multirow{2}{*}{ MICROSCOPIC GEOLOGICAL FEATURE } & \multicolumn{2}{|c|}{$k(m D)$} & \multicolumn{2}{|c|}{$\phi(\%)$} & \multicolumn{2}{|c|}{ Vp dry $(\mathrm{m} / \mathrm{s})$} & \multirow{2}{*}{ PETROGRAPHY IMAGE } \\
\hline & & Min & Max & Min & Max & Min & Max & \\
\hline RT-5 & $\begin{array}{l}\text { Sd; hd, f-mg, mod-w srtd, sbang-sbrnd, pn>cc-fl, } \\
\text { qtz, plag Felds, sli Carb, sli arg, qtz-kao-sid } \\
\text { cement }\end{array}$ & 306 & 4504 & 23.5 & 29.6 & 1591 & 2116 & $\mathrm{k}=1704 \mathrm{mD}, \varphi=24.8 \%, \mathrm{Vp}$ dry $=1943 \mathrm{~m} / \mathrm{s}$ \\
\hline RT-6 & $\begin{array}{l}\text { Sd; m hd-hd, fg, mod-w srtd, sb ang-sb rnd, } \\
\text { pl>cc>fl, qtz-chert, less pot \& plag Felds, sli Carb, } \\
\text { sli arg, coal lams, qtz-kao-ill-sid cement }\end{array}$ & 60 & 714 & 18 & 25 & 1720 & 2700 & ${ }_{\mathrm{k}=257 \mathrm{mD}, \varphi=21.3 \%, \mathrm{vpdry}=1860 \mathrm{~m} / \mathrm{s}}$ \\
\hline RT-7 & $\begin{array}{l}\text { Sd; hd, vf-fg, mod-w srtd, sbang-sb rnd, pn-cc- } \\
\text { ss>l>fl, qtz, plag Felds, sli carb, sli calc, sli coal, sli } \\
\text { arg, qtzitic, kao-ill-pyrt cement }\end{array}$ & 10 & 230 & 14.4 & 19.1 & 1838 & 3209 & $\mathrm{k}=29 \mathrm{mD}, \varphi=16.0 \%, \mathrm{vpdry}=2333 \mathrm{~m} / \mathrm{s}$ \\
\hline RT-8 & $\begin{array}{l}\text { Sd; } m \text { hd-hd, vf-fg, mod-w st, ang-sbang, pn- } \\
\text { cc>fl>ss>s, qtz, plag Felds, sli calc, sli arg, kao-ill- } \\
\text { sid cement }\end{array}$ & 4.5 & 39 & 11.8 & 17 & 1961 & 2955 & $\mathrm{k}=25 \mathrm{mD}, \varphi=16.7 \%, \mathrm{Vp}$ dry $=2550 \mathrm{~m} / \mathrm{s}$ \\
\hline RT-9 & $\begin{array}{l}\text { Sd, m hd-hd, vf-f/mg, mod-w srtd,ang-sbang, pn- } \\
\text { cc-ss>fl>s>l, qtz, plag Felds, sli calc, sli arg, kao-ill } \\
\text { cement }\end{array}$ & 1.2 & 8.9 & 10.6 & 14.7 & 2032 & 3350 & \begin{tabular}{l}
$\mathrm{k}=2.7 \mathrm{mD}, \varphi=14.1 \%, \mathrm{Vp}$ dry $=2278 \mathrm{~m} / \mathrm{s}$ \\
\hdashline$\vdots$ \\
$\vdots$
\end{tabular} \\
\hline RT-10 & $\begin{array}{l}\text { Sd; hd, vf-fg, mod-w srtd, ang-sbang/rnd, } \\
\text { cc }>\text { I>pi>fl>s, qtz,plag Felds, sli Carb, sli arg, kao-ill } \\
\text { cement }\end{array}$ & 0.44 & 1.9 & 9.6 & 12.9 & 1984 & 3067 & 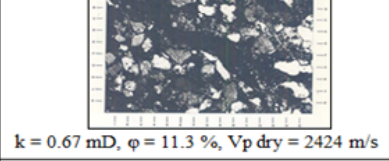 \\
\hline RT-11 & $\begin{array}{l}\text { Sd; hd, vf-fg, mod-w std, ang-sbang/rnd, } \\
\text { pn>l>fl>cc-s, qtz, plag Felds, sli calc, sli arg, kao- } \\
\text { ill cement }\end{array}$ & 0.2 & 1.2 & 4.9 & 9.72 & 2527 & 4022 & $\mathrm{k}=0.52 \mathrm{mD}, \varphi=9.72 \%, \mathrm{vpdry}=2676 \mathrm{~m} / \mathrm{s}_{2}$ \\
\hline RT-12 & $\begin{array}{l}\text { Sd; hd, vfg, mod-w srtd, ang-sbang/sb rnd, } \\
\text { pn>l>fl>cc, qtz, plag Felds, sli calcite, sli arg, coal } \\
\text { strk, kao-ill cement }\end{array}$ & 0.1 & 0.42 & 4.55 & 8 & 2603 & 3919 & $\mathrm{k}=0.16 \mathrm{mD}, \varphi=5.39 \%, \mathrm{vpdry}=3919 \mathrm{~m} / \mathrm{s}$ \\
\hline RT-13 & $\begin{array}{l}\text { Sd; hd, vfg, mod std, ang-sbang, qtz, sli calc, sli } \\
\text { arg, coal strk, clay cemented }\end{array}$ & 0.05 & 0.1 & 4.5 & 6.5 & 2471 & 4396 & No data \\
\hline RT-14 & $\begin{array}{l}\text { Sd; hd-vhd, vf, mod-w srtd, ang-sbang, quartzitic, } \\
\text { silty, sli arg, clay cemented }\end{array}$ & 0.03 & 0.07 & 2.5 & 6.26 & 2442 & 4045 & No data \\
\hline RT-15 & $\begin{array}{l}\text { Dolomitic sandstone; vhd, vf, ang-sbang, sli Carb, } \\
\text { dolo-sid cement }\end{array}$ & 0.02 & 0.02 & 3.2 & 3.4 & 4011 & 4248 & $\mathrm{k}=0.02 \mathrm{mD}, \varphi=3.2 \%, \mathrm{Vp}$ dry $=4248 \mathrm{~m} / \mathrm{s}$ \\
\hline
\end{tabular}


Line A - B drawn in Figure 4 and 5 is to indicate that, for a given rock type, the mean hydraulic radius increases toward point $B$ and all the rock members of the rock type have similar tortuosity that can be represented by a single J-Function curve. This refers to El-Khatib (1995) showing mathematically that tortuosity $\tau$ is $1 / 2 \int\left(1 / J^{2}\right) d S$. For the rock samples used in the present study, the capillary pressure data available support this theory. Figures 6 and 7 demonstrate a specific characteristic of the rock types for sandstone data set 1 and sandstone data set 2, respectively. As can be seen in these figures, each rock type tends to have its own J-Function curve that can be distinguished from the others. Now, for a rock type, the pore structure variable in Eq. (1) or Eq. (2) is controlled by pore shape factor $F_{s}$ and specific internal surface area $S_{b}$. Since both $(k / \phi)^{0.5}$ and $1 / S_{b}$ are characteristic of length, $1 / S_{b}$ may be said as the scale for the length $(k / \phi)^{0.5}$. Furthermore, according to the fractal theory (Peitgen et al., 2004 ) if the porous natural rocks obey the power law behavior as represented by Eq. (4) then the exponent $b$ is the exponent of self similarity. One may deduce, therefore, that all the members of a given rock type should have a similar $F_{s}$. If this is true, for a given rock type, one of the controlling factors of petrophysical properties is parameter $S_{b}$ in addition to variation of the content of certain materials from one member to another.
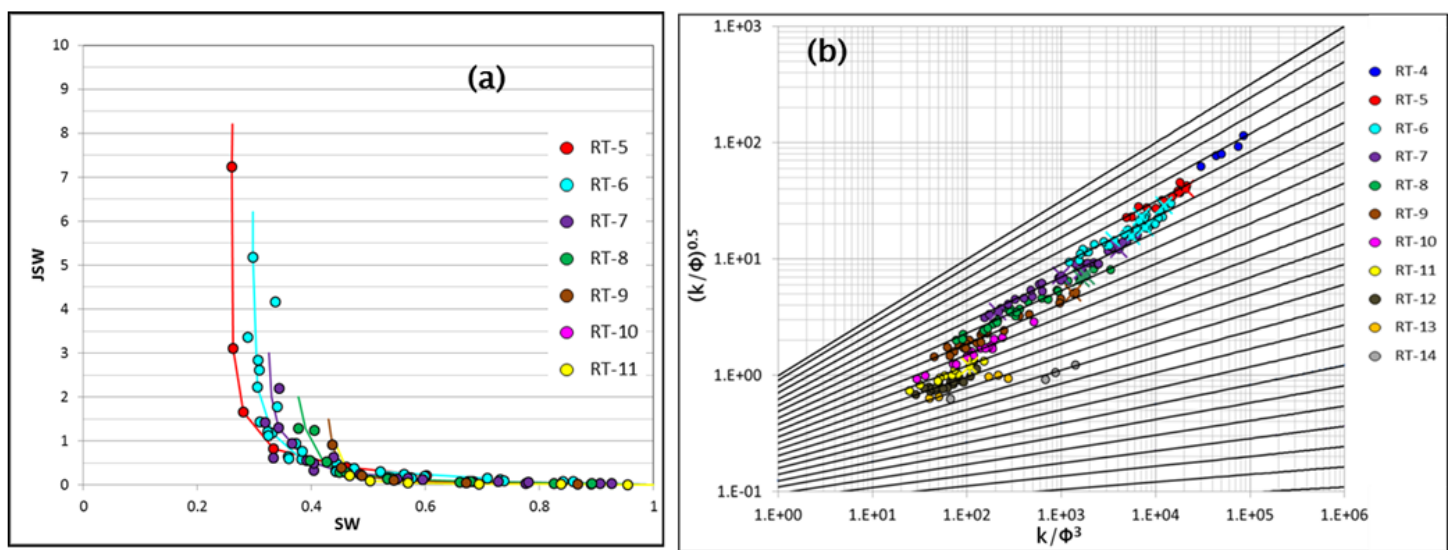

Figure 6. J-function curve (a) and pore geometry-pore structure plot (b) for data set 1 with legends $\times$ denote SCAL samples
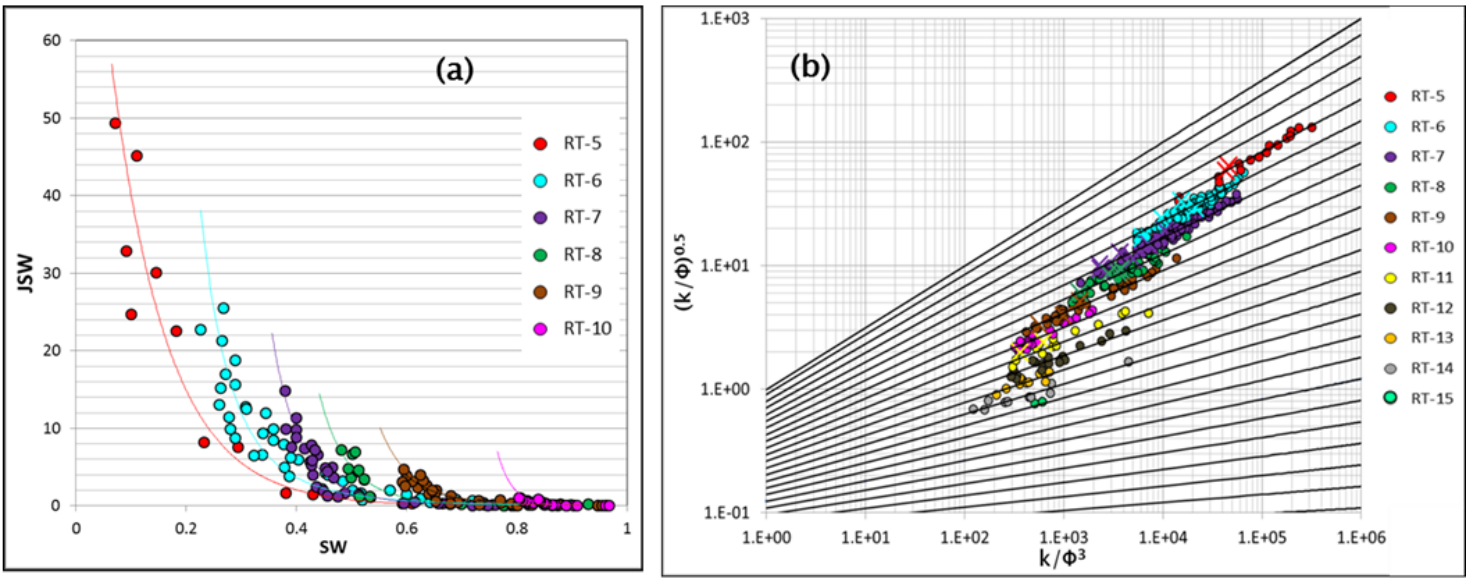

Figure 7. J-function curve (a) and pore geometry-pore structure plot (b) for data set 2 with legends $\times$ denote SCAL samples

\subsection{Effect of Pore Geometry on Dry P-Wave Velocity $\left(V_{p d}\right)$}

The data of dry P-wave velocity $\left(V_{p d}\right)$ obtained from the measurements conducted on all the rock samples were sorted according to the rock types. Figure 8 shows the plots of $V_{p d}$ against the pore geometry variable $(k / \phi)^{0.5}$ for the data set 1 on the left side and the data set 2 on the right side of the figure. The two data sets have the same pattern where all the data points were separated to form clusters, each specifically representing a certain rock type. Without grouping the rock samples into rock types, the spreadness of the data points is quite large although 
there is a trend of increasing $V_{p d}$ as the pore geometry term decreases. This is mainly due to combined effects of porosity, grain sizes and shapes, and rock hardness. In general, for ungrouped rocks, a decrease in porosity results in a reduction of the permeability. For the sandstones under this work, the samples with very low porosity are characterized, in addition to finer grains, by the presense of denser materials such as calcite mineral, more cementing materials, and an increase in rock hardness. Such characteristics cause the effect of porosity more pronounced on $V_{p d}$.
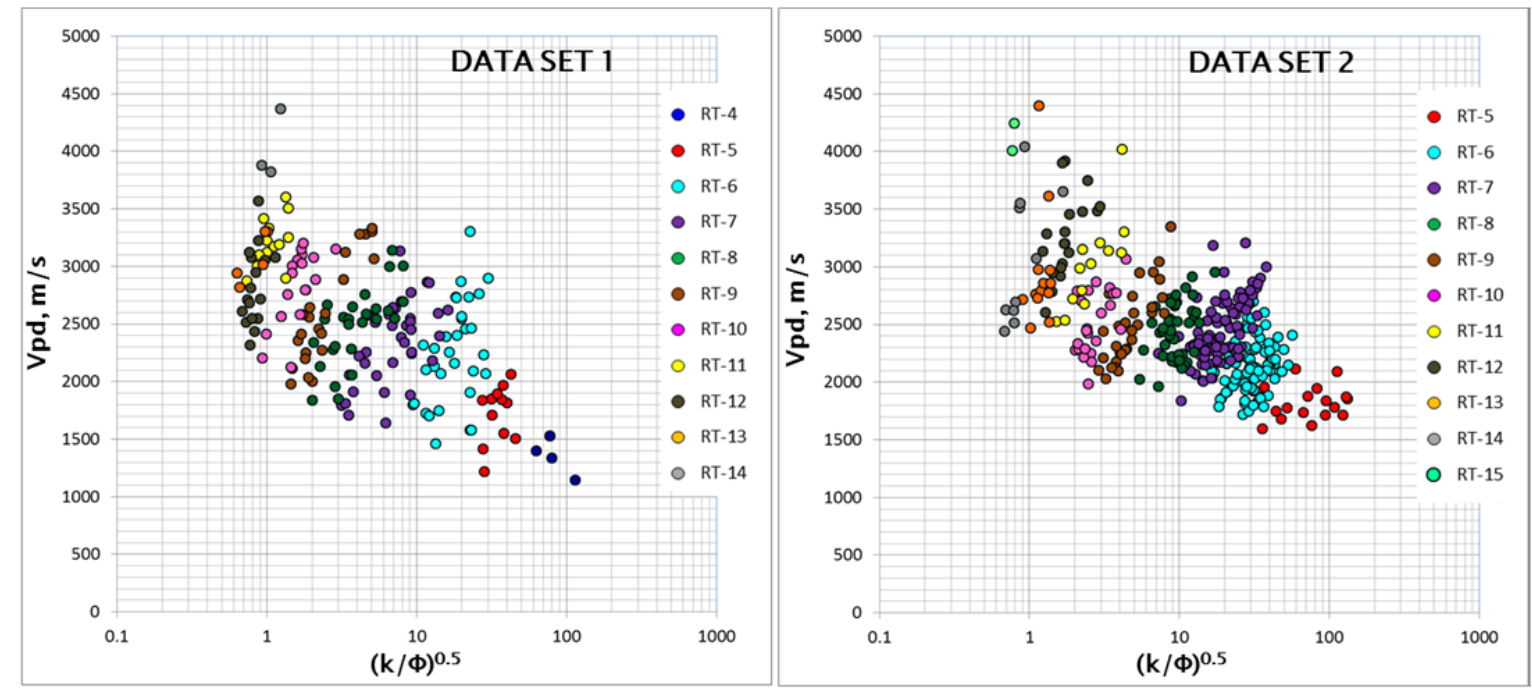

Figure 8 . The influence of pore geometry $(k / \phi)^{0.5}$ on dry P-wave velocity $\left(V_{p d}\right)$ for data set 1 and 2

It is more interesting to analyze the relationship between $V_{p d}$ and pore geometry on the rock type basis. Figure 8 demonstrates that all rock types have the same behavior in that $V_{p d}$ tends to get higher as pore geometry variable increases. As pore geometry here is equivalent to mean hydraulic radius, $V_{p d}$ increases with this radius. Starting with the poorest rock quality, the most left data points of several rock types seemly have the same trend line (see Figure 8). This behavior is not only due to both very low porosity and very low permeability but also both rock textures and the level of rock hardness are about the same. This level is determined by both the type and content or volume of the cementing material. The higher the density of the material and the larger the content, the harder the rock is. Furthermore, the more the volume of cementing materials, the lower the porosity would be. Since no data of the content of such materials is available for the sandstones used here, it could be expected that the lower both porosity and permeability measured on the samples of poorer rock types, typically shown in the last column of the tables, are probably due to higher volume of the cementing materials. It can be seen also in the second column of the tables that the level of hardness for the poorest rock types is hard to very hard. The cementing materials identified from thin section data are clays, calcite, pyrite, siderite, and dolomite (see Tables 2 and 3). Therefore, the difference that makes higher velocity $V_{p d}$ for the poorest rock types is most likely a higher percentage of cementing materials and the type such as illite, calcite, dolomite, and siderite.

For rock types of better quality, those with smaller rock type numbers, the data points of neighbouring rock types are clearly separated. The cementing materials in these rock types are dominated by clays. The better the rock type quality, the lesser the amount of cementing materials, the stronger the role of pore geometry. As has been discussed above, pore geometry in each rock type is strongly controlled by the value of $S_{b}$. According to Eq. (4), pore geometry variable is inversely proportional to $S_{b}$ squared. Porous rocks made up of smaller grains size tend to have higher $S_{b}$. Oppositely, larger grain size produces lower $S_{b}$. In cases of the sandstones employed here, the data of grain sizes are available for the two data sets. Although the amount is limited, the data of grain size versus pore geometry variable are plotted as presented in Figures 9(a) and 10(a) for data set 1 and data set 2, respectively. It can be seen in these figures that pore geometry variable tends to increase with grain size.

It has been described above that any given rock type has its own similarity in both tortuosity and pore shape factor. Thus, the only difference among the members of a rock type is just $S_{b}$. According to Eq. (1), a lower $S_{b}$ will result in a higher $(k / \phi)^{0.5}$. A lower $S_{b}$ can be resulted from lesser number of pores or a decrease in porosity but relative bigger pore size. Thus, porosity reduction that results in an increase in $(k / \phi)^{0.5}$ is an indication of a 
larger mean hydraulic pore size or a bigger average pore throat size. It may be concluded that, for a given rock type, the increase in $V_{p d}$ with pore geometry $(k / \phi)^{0.5}$ is due to a decrease in porosity followed by an increase in the average pore throat size. However, for a rock type with members demonstrating in the way around in that $V_{p d}$ decreases as $(k / \phi)^{0.5}$ increases, the influence of porosity may be much stronger than that of the mean hydraulic pore size or pore throat size. This will be described further in the next section with some examples of the related data presented later in Table 4.

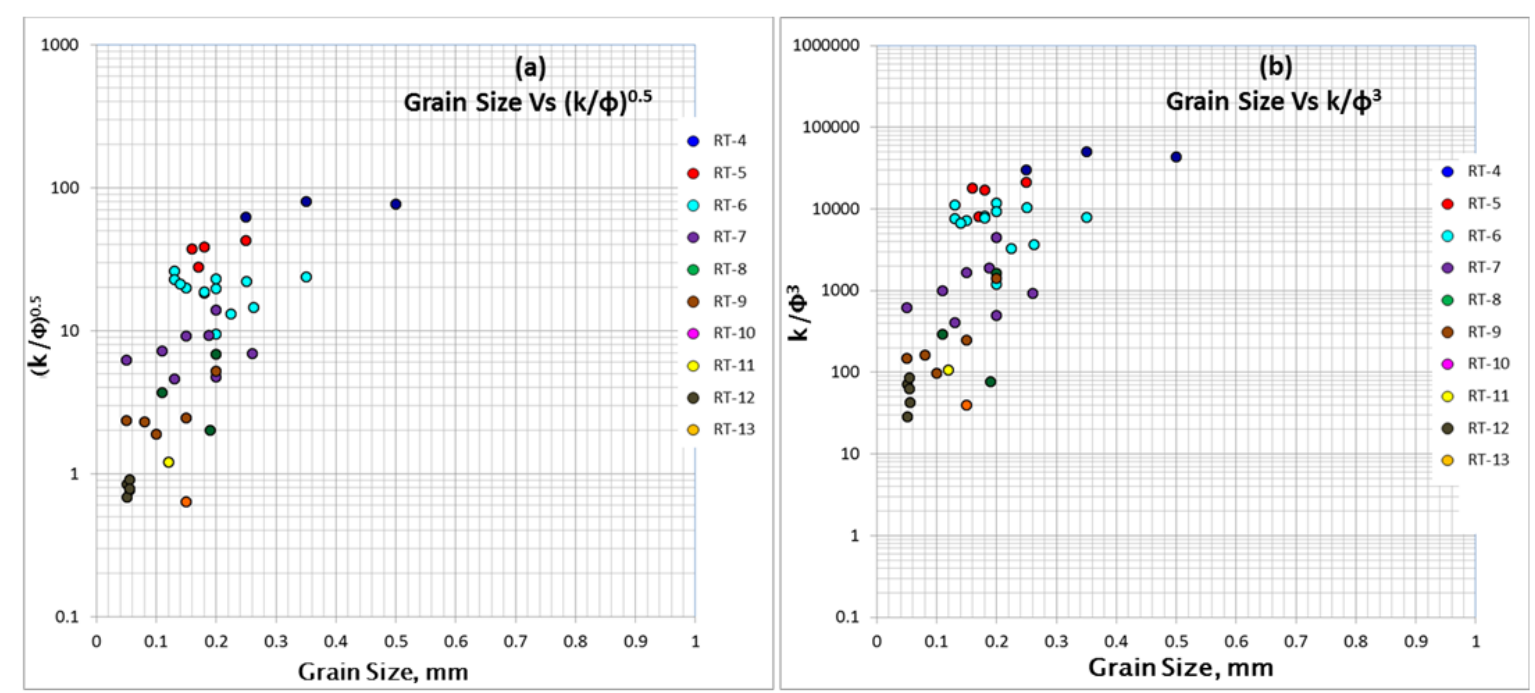

Figure 9. Relations of pore geometry $(k / \phi)^{0.5}(\mathbf{a})$ and pore structure $\left(k / \phi^{3}\right)(\mathbf{b})$ with grain size for data set 1
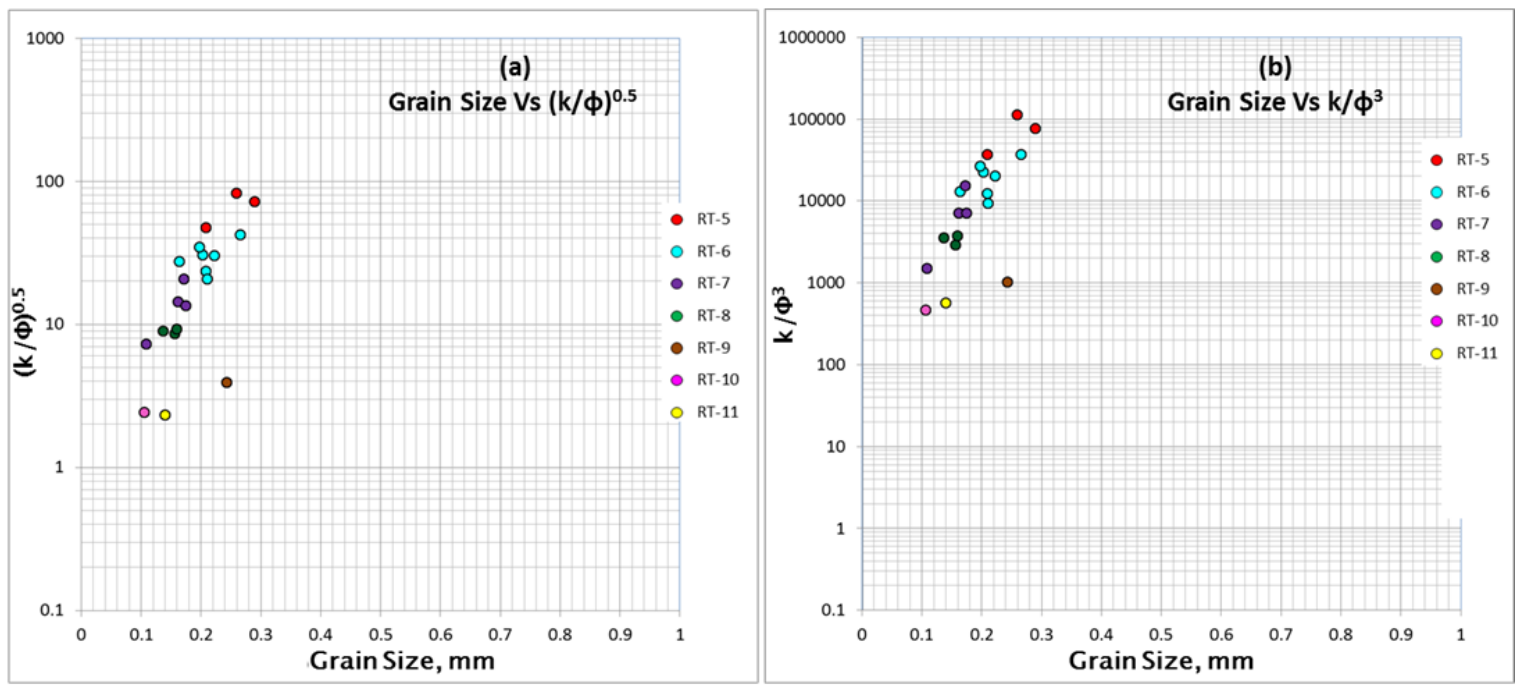

Figure 10. Relations of pore geometry $(k / \phi)^{0.5}(\mathbf{a})$ and pore structure $\left(k / \phi^{3}\right)(\mathbf{b})$ with grain size for data set 2

\subsection{Effect of Pore Structure $\left(k / \phi^{3}\right)$ on Dry P-Wave Velocity $\left(V_{p d}\right)$}

According to Eqs. (1) and (2), parameters that affect either pore geometry or pore structure variable are principally the same. The effect of grain size on pore structure is also much the same as can be seen in Figures 9(b) and 10(b), showing an increase in grain size gives a higher pore structure variable. The effect of grain size on pore structure may be partly explained via the effect of grain size on $S_{b}$ as just described above. More than this, Eq. (2) states that porous rocks with lesser tortuosity, simpler pore shapes or a lower shape factor, and a lower specific internal surface area would have a higher value of the pore stucture term. These charateristics are normaly owned by good to excellent quality rock types. Conversely, lower quality rock types are those with higher tortuosity and more complex pore shapes or a higher shape factor, resulting in a lower value of pore 
structure term, more complex pore structure.

The pore structure variable is much higher in value than that of pore geometry one as the former is inversely proportional to porosity to the power of three. A very low porosity combined with a relatively high permeability would yield high value for the pore structure variable. Figure 11 demonstrates the relation of pore structure variable to $V_{p d}$ for sandstones data set 1 and data set 2. It looks much the same like the relationship between pore geometry variable and $V_{p d}$ (see Figure 8). However, as depicted in Figure 11, the separation of the data points of several lower quality rock types is less clear due to overlapping when compared with that seen in Figure 8 for the effect of pore geometry on $V_{p d}$. This is because the numerical values of pore structure variable among the very low quality rock types are closely the same.

Even though, as can be seen in Figure 11, some data points of several rock types behave differently in that $V_{p d}$ decreases or is relatively constant as $\left(k / \phi^{3}\right)$ increases. Table 4 typically shows such a behavior. It would be expected that $V_{p d}$ increases with permeability as shown by Klimentos (1991). This is true in our cases here for any given rock type as long as the increase in permeability is followed by porosity reduction. However, Table 3 says quite differently. This behavior can be explained as the following, as described in the previous section. The concept of rock typing or grouping as given by Eq. (4) assumes the same tortuosity and pore shape for all the members of a rock type or group. Consequently to the group, $k / \phi^{3}$ is strongly influenced by specific internal surface area $S_{b}$. Therefore, the typical cases presented in Table 4 may be interpreted that, by ignoring the effect of materials composing the samples, the effect of the permeability increase on the velocity was probably suppressed by the influence of higher both porosity and $S_{b}$ because the increase in these two parameters reduces the velocity.
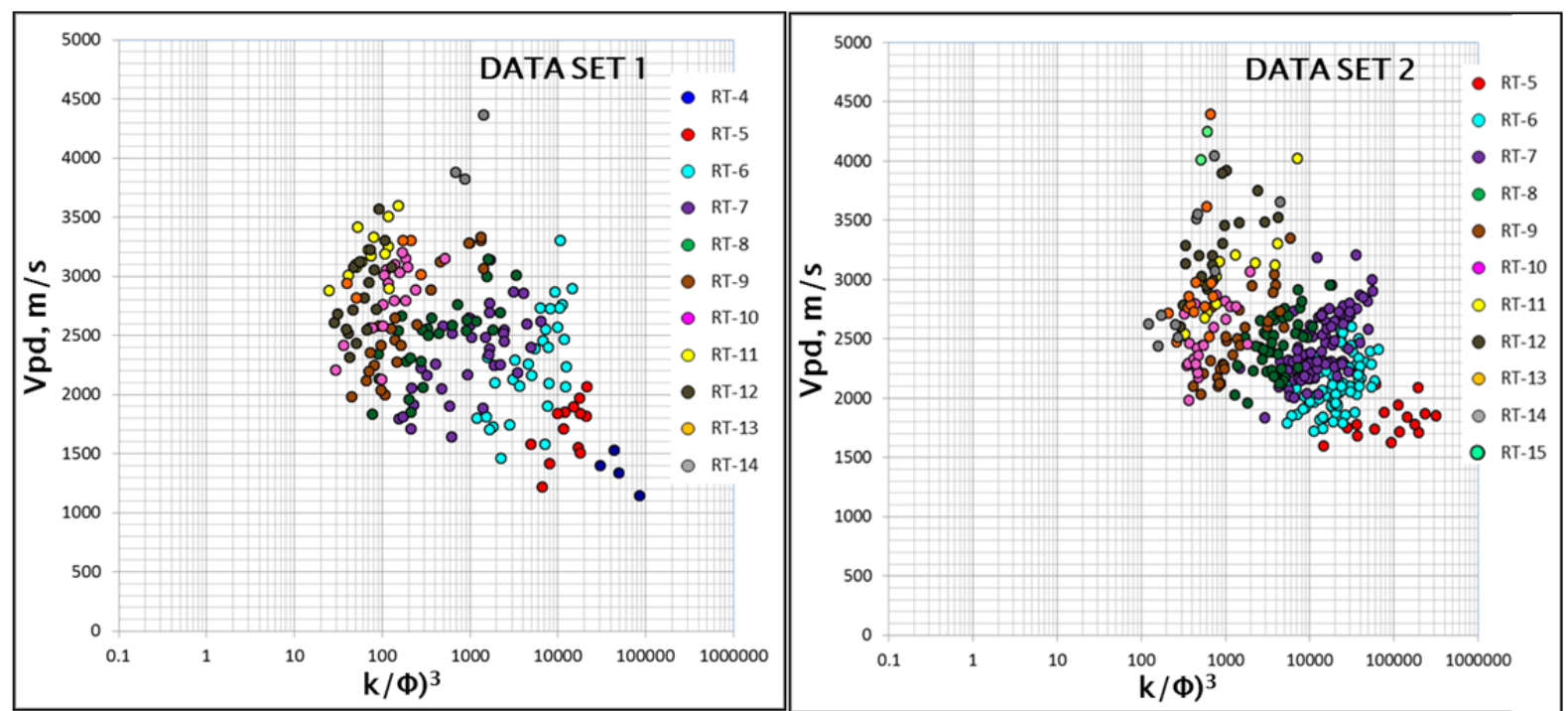

Figure 11. The influence of pore structure $\left(k / \phi^{3}\right)$ on dry P-wave velocity $\left(V_{p d}\right)$ for data set 1 and 2

Table 4. Typical influence of porosity and permeability on $(k / \phi)^{0.5},\left(k / \phi^{3}\right)$ and $V_{p d}$

\begin{tabular}{ccccccccc}
\hline \multirow{2}{*}{ Data Set } & Rock & Sample & $\phi$ & $k$ & \multirow{2}{*}{$(k / \phi)^{0.5}$} & $\left(k / \phi^{3}\right)$ & $V_{p d}$ \\
\cline { 2 - 4 } \cline { 8 - 9 } & Type & No. & fraction & $\mathrm{mD}$ & & $\mathrm{m} / \mathrm{s}$ \\
1 & 4 & 16 & 0.360 & 1406 & 62 & 30135 & 1397.4 \\
& & 76 & 0.393 & 5153 & 114 & 84830 & 1146.1 \\
2 & 5 & 15 & 0.266 & 520 & 44 & 27629 & 1750.0 \\
& & 35 & 0.273 & 2393 & 94 & 117613 & 1714.3 \\
2 & 6 & 8 & 0.225 & 81 & 19 & 7111 & 1862.7 \\
& & 34 & 0.211 & 321 & 39 & 34171 & 1882.8 \\
\hline
\end{tabular}

\subsection{Dry P-Wave Velocity $\left(V_{p d}\right)$ Prediction}

The relationship between P-wave velocity and combined permeability-porosity is rarely found in the literature. 
Several attempts were made to relate P-wave velocity with porosity and clay content (Han et al., 1986; Klimentos, 1991; Vernik, 1992). Prasad (2003) found that the velocity correlated systematically with permeability when his rock samples were grouped by applying the hydraulic unit concept. It may be preferable to predict P-wave velocity based on two important reservoir parameters, permeability and porosity. The results presented in Figures 8 and 11 can then be used to develop correlations for those rock properties involved.

Since the measurements of all the rock properties were conducted at ambient conditions, it is assumed that the fluid residing the pores is air and the P-wave velocity for air is about $331.45 \mathrm{~m} / \mathrm{s}$. Furthermore, the concept of rock typing implemented in this study says that all rock types that includes ideal capillary systems have a convergence point at which both pore geometry and structure of the pores of all the porous systems are indistinguishable (Wibowo, 2014). This author determined the convergence point at $(k / \phi)^{0.5}=0.045$ and $k / \phi^{3}=$ 0.002. This means that the porous rocks, at this point of convergence have the same property, possibly including the wave velocity $V_{p d}$. Since no distinction of both pore geometry and structure could be made among all rock types at the convergence point, it is assumed for practical purposes that this situation holds for infinitely small capillary tubes a porosity value of 1.0 , yielding $V_{p}$ of the fluid containing the pores. Consequently, the correlations of $V_{p d}$ against either $(k / \phi)^{0.5}$ or $k / \phi^{3}$ developed in the present study has a convergence point at a point $\left(V_{p d},(k / \phi)^{0.5}\right)=(331,0.045)$ or $\left(V_{p d}, k / \phi^{3}\right)=(331,0.002)$. Taking these as the requirements for generating the regression line for each rock type established, the results are shown in Figures 12 and 13, respectively, for data set 1 and data set 2. The summary of the regression equations is given in Tables A-1 and A-2. As depicted in Table A- 1 , the coefficient correlations $R^{2}$ for $V_{p d}$ versus $(k / \phi)^{0.5}$ range from 0.814 to 0.987 for data set 1 and from 0.778 to 0.999 for data set 2. Table A-2, which is for $V_{p d}$ versus $k / \phi^{3}$, exhibits $R^{2}$ ranging from 0.850 to 0.982 for data set 1 and from 0.832 to 0.999 for data set 2 . These results enable one to generalize the relationship for $V_{p d}$ versus $(k / \phi)^{0.5}$ and $V_{p d}$ versus $k / \phi^{3}$, respectively, in the forms of Eqs. (5) and (6) below.

$$
\begin{aligned}
& V_{p d}=c\left[(k / \phi)^{0.5}\right]^{p} \\
& V_{p d}=d\left[k / \phi^{3}\right]^{q}
\end{aligned}
$$

where $c$ and $d$ are constants and $p$ and $q$ are exponents, which all rock type dependence.
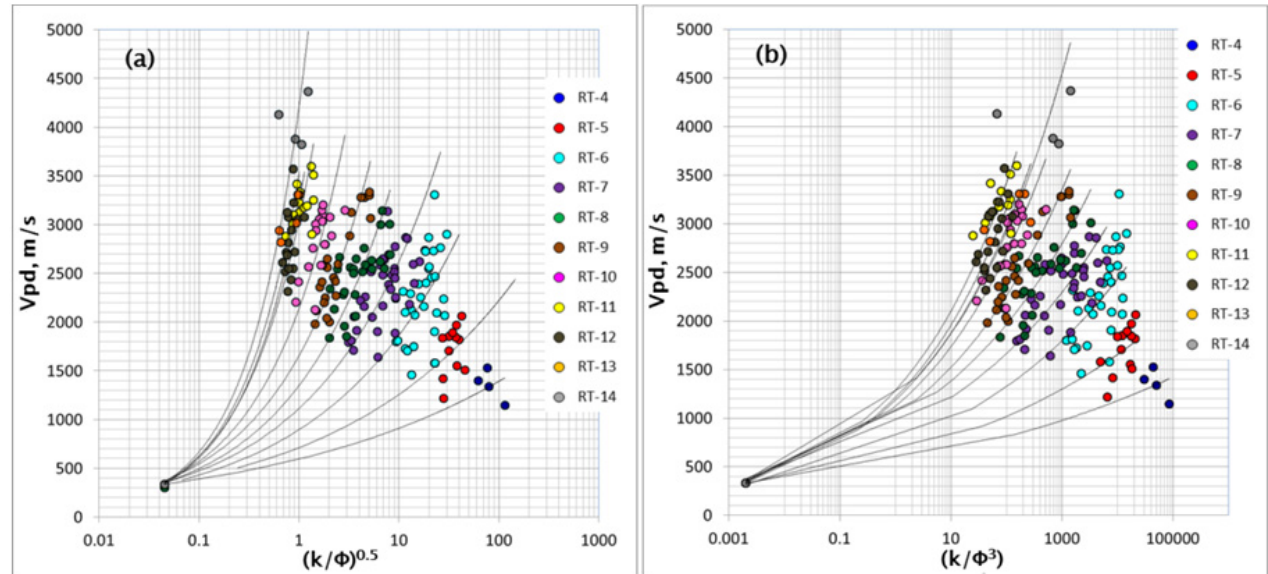

Figure 12. Regression lines for $V_{p d}$ Vs. $(k / \phi)^{0.5}$ (a) and $V_{p d}$ vs. $\left(k / \phi^{3}\right)(\mathbf{b})$ for data set 1 


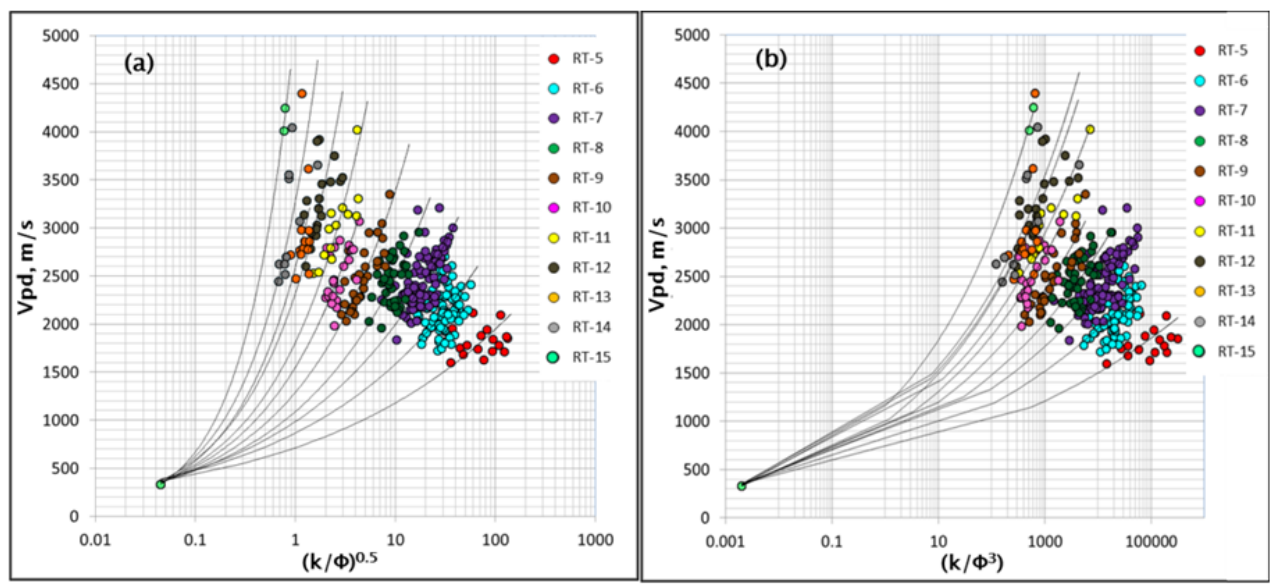

Figure 13. Regression lines for $V_{p d}$ Vs. $(k / \phi)^{0.5}(\mathbf{a})$ and $V_{p d}$ vs. $\left(k / \phi^{3}\right)(\mathbf{b})$ for data set 2

Application of the regression formula of each rock type as shown in Tables A-1 and A-2 for predicting $V_{p d}$ was performed. By using permeability and porosity values of the samples of the corresponding rock type, the predicted $V_{p d}$ was then compared with the values of $V_{p d}$ measured. For $V_{p d}$ against $(k / \phi)^{0.5}$, the comparisons are exhibited in Figures 14a and 14b, giving average relative errors $A R E=10.4 \%$ and $7.7 \%$, respectively, for data set 1 and data set 2. Likewise for $V_{p d}$ versus $k / \phi^{3}$, the predictions are presented in Figure 15a and 15b, yielding $A R E$ $=9.0 \%$ and $6.8 \%$, respectively, for data set 1 and data set 2 , which are lower than those obtained from $V_{p d}$ against $(k / \phi)^{0.5}$.
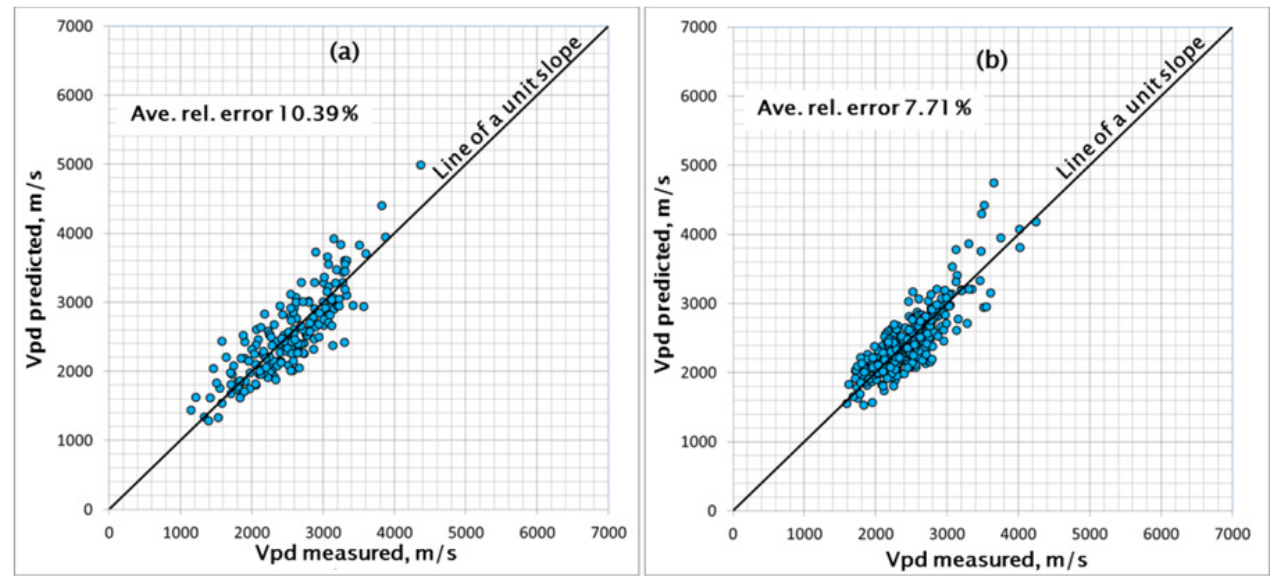

Figure 14. Predicted versus measured $V_{p d}$ based on $(k / \phi)^{0.5}$ for rock typed samples data set $1(\mathbf{a})$ and data set $2(\mathbf{b})$
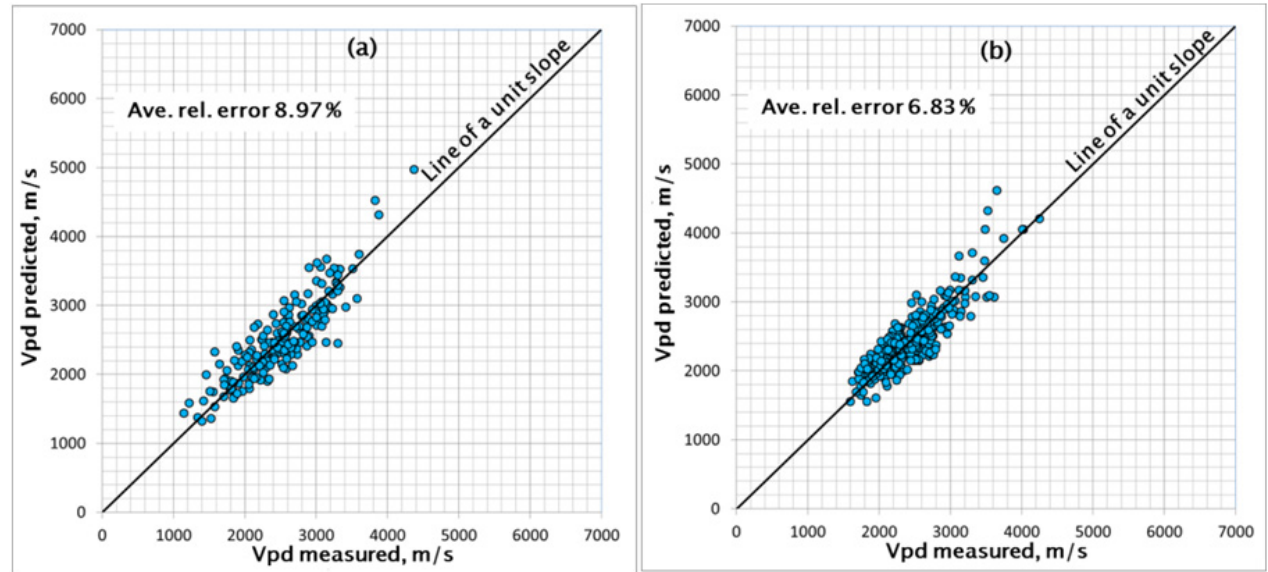

Figure 15. Predicted versus measured $V_{p d}$ based on $\left(k / \phi^{3}\right)$ for rock typed samples data set $1(\mathbf{a})$ and data set 2 (b) 
When rock grouping or rock typing was not made, the relationships of $V_{p d}$ with $(k / \phi)^{0.5}$ and $k / \phi^{3}$, respectively, are shown in Figures 16 and 17, depicting also both the equations and the correlation coefficients $R^{2}$ of the trend lines. As expected, the $R^{2}$ is very low for all the relations. The use of these equations by plugging in the permeability and porosity values of each data set to calculate $V_{p d}$ and comparisons made with the measured $V_{p d}$ result in those given in Figures A-1 and A-2, respectively, for data set 1 and data set 2. The average relative errors $A R E$ calculated for $V_{p d}$ versus $(k / \phi)^{0.5}$ are $15.3 \%$ and $11.4 \%$, respectively, for data set 1 and data set 2 . The prediction based on $V_{p d}$ against $k / \phi^{3}$ yields $A R E=16.9 \%$ and $12.8 \%$ for dataset 1 and data set 2, respectively. These average relative errors are considerably higher than those resulted from rock grouping above.
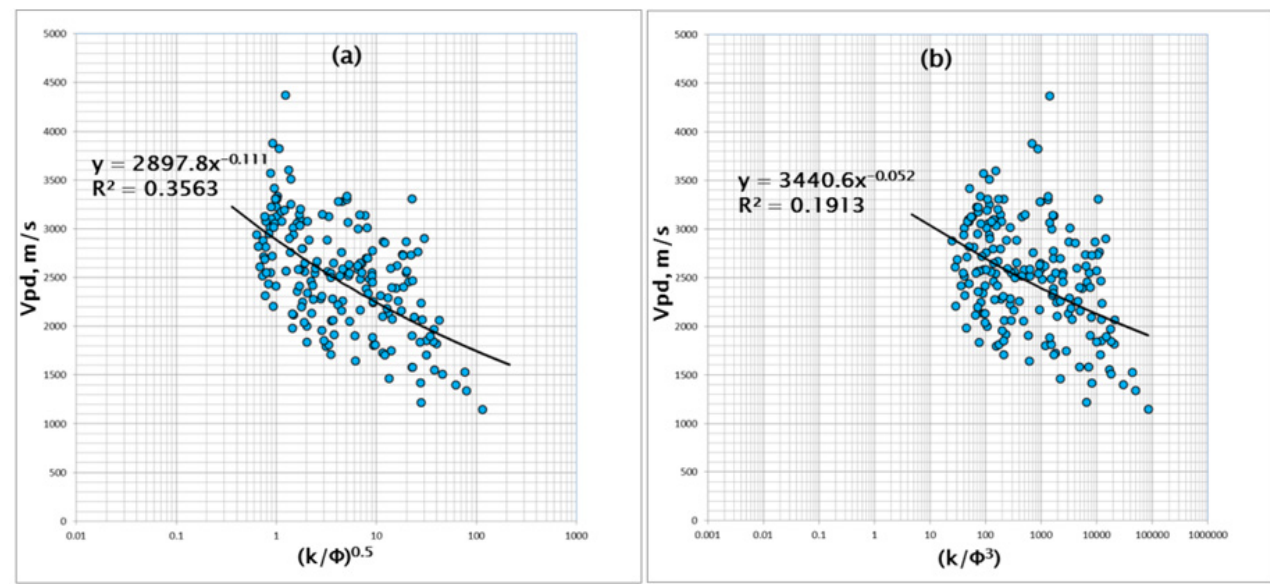

Figure 16. Trend line on ungrouped rocks for $V_{p d}$ vs $(k / \phi)^{0.5}(\mathbf{a})$ and $V_{p d}$ vs. $\left(k / \phi^{3}\right)(\mathbf{b})$ for data set 1
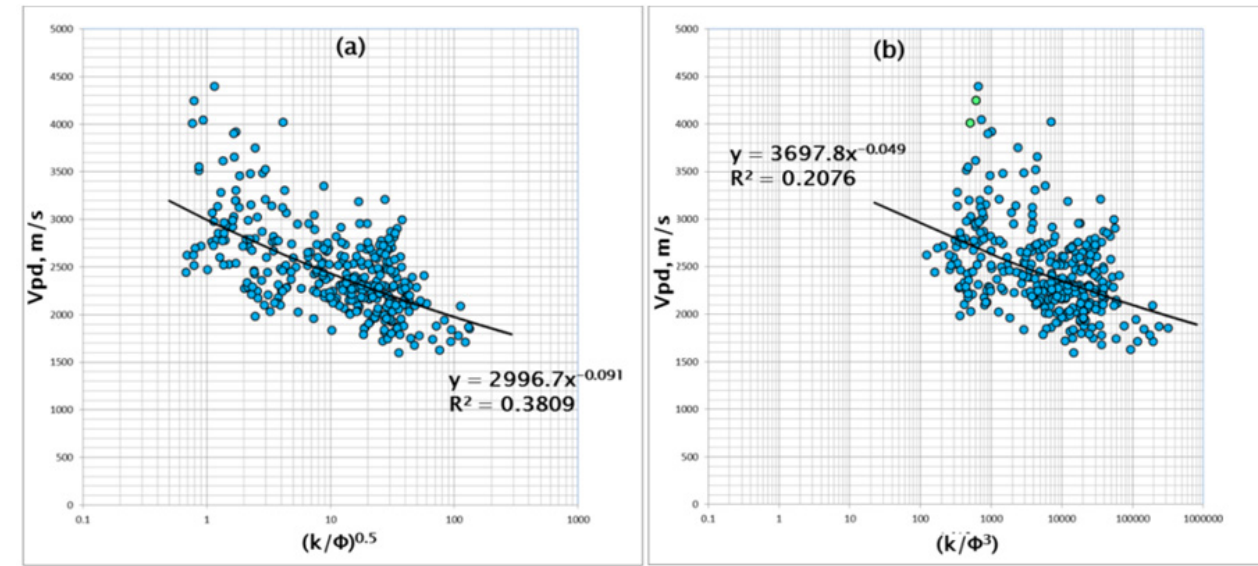

Figure 17. Trend line on ungrouped rocks for $V_{p d}$ vs $(k / \phi)^{0.5}(\mathbf{a})$ and $V_{p d}$ vs. $\left(k / \phi^{3}\right)(\mathbf{b})$ for data set 1

\section{Conclusion}

1. The effect of pore attributes, pore geometry and pore structure, on dry P-wave velocity at ambient conditions have been conducted for porous and permeable sandstones.

2. Two data sets of sandstones were employed. Grouping the rock samples on the basis of pore structure similarity, similarity in both tortuosity and pore shape factor, provides a clearer explanation of the effects of pore attributes on dry P-wave velocity.

3. For a given rock group or rock type, an increase in either pore geometry or pore structure is due to a decrease in both specific internal surface area and porosity but producing a larger mean hydraulic radius, which all give rise to an increase in dry P-wave velocity. 
4. The effect of permeability increase on dry P-wave velocity could be suppressed by the influence of higher both porosity and specific internal surface area because the increase in these two parameters reduces pore geometry and thus the velocity.

5. Prediction of dry P-wave velocity was best obtained when the rock samples were rock typed and on the basis of relation between $V_{p d}$ and pore structure $k / \phi^{3}$, giving relative errors of $9.0 \%$ and $6.8 \%$ for data set 1 and data set 2 , respectively.

\section{Acknowledgments}

One of the authors would like to thank the Trisakti University for the scholarship to enroll for doctoral program at the Petroleum Engineering Study Program, Institut Teknologi Bandung, Geophysical Laboratory FTKE Trisakti University for providing a SonicViewer tool, and PPPTMGB "Lemigas" for the core samples and the corresponding petrographycal analysis data provided for his research work.

\section{References}

Amaefule, J. O., Altunbay, M., Tiab, D., Kersey, D. G., \& Keelan, D. K. (1993). Enhanced Reservoir Description Using Core and Log Data to Identify Hydraulic (Flow) Units and Predict Permeability in Uncored Intervals/Wells, Paper SPE 26436 presented at the $68^{\text {th }}$ Annual Technical Conference and Exhibition of the SPE held in Houston, Texas, October 3-6.

Bashah, N. S. I., \& Pierson, J. (2012). Quantification of Pore Structure in a Miocene Carbonate Build-Up of Central Luconia, Sarawak and Its Relationship to Sonic Velocity. International Petroleum Technology Conference, 14652.

Burdine, N. T., Gournay, L. S., \& Reichertz, P. P. (1950). Pore Size Distribution of Petroleum Reservoir Rocks, A.I.M.E., 189. http://dx.doi.org/10.2118/950195-g

El-Khatib, N. (1995). Development of a Modified Capillary Pressure-J Function, Paper SPE 29890 presented at the SPE Middle East Oil Show held in Bahrain, March 11-14.

Fabricius, I. L., Baechle, G., Eberli, G. P., \& Weger, R. (2007). Estimating Permeability of Carbonate Rocks From Porosity and Vp/Vs, Geophysics, 72, 5. http://dx.doi.org/10.1190/1.2756081

Fabricius, I. L., Baechle, G., Eberli, G. P., \& Weger, R. (2010). Elastic Moduli of Dry and Water-Saturated Carbonates - Effect of Depositional Texture, Porosity, and Permeability, Geophysics, 75, 3. http://dx.doi.org/10.1190/1.3374690

Han, D. H., Nur, A., \& Morgan, D. (1986). Effects of Porosity and Clay Content on Wave Velocities in Sandstones, Geophysics, 51, 2093-2107. http://dx.doi.org/10.1190/1.1442062

Harmsen, G. J. (1955). The Concept "Hydraulic Radius" in Porous Media. Petroleum Transactions, AIME, 204, 274-277.

Klimentos, T. (1991). The Effects of Porosity-Permeability-Clay Content on The Velocity of Compressional Waves, Geophysics, 56(12), 1930 - 1939. http://dx.doi.org/10.1190/1.1443004

Leverette, M.C. (1940). Capillary Behavior in Porous Solids. Petroleum Technology, 1223, 152-169.

Marion, D., Nur, A., \& Alabert, F. (1989). Modelling The Relationships Between Sonic Velocity, Porosity, Permeability, And Shaliness In Sand, Shale and Shaley Sand, SPWLA.

Marion, D., Nur, A., \& Yin, H. D. (1992). Compressional Velocity and Porosity in Sand-Clay Mixtures. Geophysics, 57(4), 554-563. http://dx.doi.org/10.1190/1.1443269

Mavko, G., Mukerji, T., \& Dvorkin, J. (2009). The Rock Physics Handbook (2nd ed). Cambridge University. http://dx.doi.org/10.1017/CBO9780511626753

Minear, J. W., \& Welex (1982). Clay Models and Acoustic Velocities, Society of Petroleum Engineers, 11031.

Mokhtar, E. A., Vega, S., Hassan, A. A., \& Baloushi, M. N. M. A. (2010). Rock Physics Characterization Using Acoustic Velocity Measurements On Late Cretaceous Carbonate Rocks From the Middle East, Society of Petroleum Engineers, 138649.

Nur, A., Mavko, G., Dvorkin, J., \& Gal, D. (1995). Critical porosity: the key to relating physical properties to porosity in rocks, In Proc. 65th Ann. Int. Meeting, Society of Exploration Geophysicists, vol. 878. Tulsa. http://dx.doi.org/10.1190/1.1887540

Peitgen, H. O., Jurgens, H., \& Saupe, D. (2004). Chaos and Fractals: New Frontiers of Science, Springer 
Science. http://dx.doi.org/10.1007/b97624

Permadi, P., \& Susilo, A. (2009). Permeability Prediction and Characteristics of Pore Structure and Geometry as Inferred From Core Data, Society of Petroleum Engineers, 125350.

Permadi, P., \& Wibowo, A. S. (2013). Kozeny's Equation for Better Core Analysis, SCA, 048.

Prasad, M. (2003). Velocity-Permeability Relations Within Hydraulic Units, Geophysics, 68, 108-117. http://dx.doi.org/10.1190/1.1543198

Rahman, M. H., \& Pierson, B. J. (2011). Vp-Vs Ratio Sensitivity to Pressure, Fluid, and Lithology Changes in Tight Gas Sandstones, SEG Annual Meeting.

Scheidegger, A. E. (1959). The Physics of Flow Through Porous Media, University of Toronto Press, Canada, pp. $112-133$

Vernik, L. (1992). Predicting Lithology and Reservoir Quality from Acoustic Velocities Based on Petrophysical Classification of Siliciclastics, Society of Exploration Geophysicists.

Verwer ,K., Eberli G., Baechle, G., \& Weger, R. (2010). Effect of Carbonate Pore Structure on Dynamic Shear Moduli, Geophysics, 75, 1. http://dx.doi.org/10.1190/1.3280225

Weger, R. J., \& Eberli, G. P. (2009). Quantification of Pore Structure and Its Effect on Sonic Velocity and Permeability on Carbonate. AAPG Bulletin, 93(10), 1297-1317. http://dx.doi.org/10.1306/05270909001

Wibowo, A. S. (2014). Karakterisasi Batuan Karbonat Berdasarkan Geometri dan Struktur Pori-Pori (Doctoral dissertation). Institut Teknologi Bandung, Indonesia.

Wibowo, A. S., \& Permadi, P. (2013). A Type Curve for Carbonates Rock Typing, International Petroleum Technology Conference, 16663. http://dx.doi.org/10.2523/IPTC-16663-MS

Xu, S., \& Payne, M. A. (2009). Modeling Elastic Properties in Carbonate Rocks, TLE.

\section{Appendix}

Table A-1. Summary of the regression equations of $V_{p d}$ vs $(k / \phi)^{0.5}$ for data set 1 and 2

\begin{tabular}{|c|c|c|c|c|}
\hline \multirow{2}{*}{ RT } & \multicolumn{4}{|c|}{ Regression Equations from $V_{p d}$ vs $(k / \phi)^{0.5}$ for data sets 1 and 2} \\
\hline & Data set 1 & $R^{2}$ & Data set 2 & $R^{2}$ \\
\hline 4 & $V_{p d}=588.14\left((k / \phi)^{0.5}\right)^{0.188}$ & 0.879 & - & - \\
\hline 5 & $V_{p d}=711.63\left((k / \phi)^{0.5}\right)^{0.2471}$ & 0.916 & $V_{p d}=714.03\left((k / \phi)^{0.5}\right)^{0.2178}$ & 0.918 \\
\hline 6 & $V_{p d}=896.73\left((k / \phi)^{0.5}\right)^{0.318}$ & 0.814 & $V_{p d}=867.12\left((k / \phi)^{0.5}\right)^{0.2617}$ & 0.778 \\
\hline 7 & $V_{p d}=1114.1\left((k / \phi)^{0.5}\right)^{0.3718}$ & 0.907 & $V_{p d}=985.71\left((k / \phi)^{0.5}\right)^{0.3064}$ & 0.849 \\
\hline 8 & $V_{p d}=1349.6\left((k / \phi)^{0.5}\right)^{0.4339}$ & 0.941 & $V_{p d}=1090.3\left((k / \phi)^{0.5}\right)^{0.3583}$ & 0.898 \\
\hline 9 & $V_{p d}=1655.6\left((k / \phi)^{0.5}\right)^{0.4807}$ & 0.954 & $V_{p d}=1290.3\left((k / \phi)^{0.5}\right)^{0.4186}$ & 0.952 \\
\hline 10 & $V_{p d}=2139.4\left((k / \phi)^{0.5}\right)^{0.5734}$ & 0.951 & $V_{p d}=1550.4\left((k / \phi)^{0.5}\right)^{0.4771}$ & 0.939 \\
\hline 11 & $V_{p d}=3047.9\left((k / \phi)^{0.5}\right)^{0.6872}$ & 0.960 & $V_{p d}=1809\left((k / \phi)^{0.5}\right)^{0.5239}$ & 0.973 \\
\hline 12 & $V_{p d}=3231.3\left((k / \phi)^{0.5}\right)^{0.7271}$ & 0.957 & $V_{p d}=2319.1\left((k / \phi)^{0.5}\right)^{0.5938}$ & 0.944 \\
\hline 13 & $V_{p d}=3523.4\left((k / \phi)^{0.5}\right)^{0.7512}$ & 0.987 & $V_{p d}=2591.8\left((k / \phi)^{0.5}\right)^{0.6538}$ & 0.932 \\
\hline 14 & $V_{p d}=4210.5\left((k / \phi)^{0.5}\right)^{0.7989}$ & 0.967 & $V_{p d}=3277.9\left((k / \phi)^{0.5}\right)^{0.7195}$ & 0.949 \\
\hline 15 & - & - & $V_{p d}=5150.7\left((k / \phi)^{0.5}\right)^{0.8847}$ & 0.999 \\
\hline
\end{tabular}

Table A-2. Summary of the regression equations of $V_{p d}$ vs $\left(k / \phi^{3}\right)$ for data set 1 and 2

\begin{tabular}{ccccc}
\hline \multirow{2}{*}{ RT } & \multicolumn{5}{c}{ Regression Equations from $V_{p d}$ vs $\left(k / \phi^{3}\right)$ for data sets 1 and 2 } \\
& Data set 1 & $R^{2}$ & Data set 2 & $R^{2}$ \\
\hline 4 & $V_{p d}=551.73\left(k / \phi^{3}\right)^{0.0846}$ & 0.887 & - & - \\
5 & $V_{p d}=627.9\left(k / \phi^{3}\right)^{0.1052}$ & 0.931 & $V_{p d}=634.38\left(\mathrm{k} / \phi^{3}\right)^{0.0935}$ & 0.933 \\
6 & $V_{p d}=721.1\left(\mathrm{k} / \phi^{3}\right)^{0.1321}$ & 0.850 & $V_{p d}=705.62\left(\mathrm{k} / \phi^{3}\right)^{0.1109}$ & 0.832 \\
\hline
\end{tabular}




\begin{tabular}{ccccc}
\hline 7 & $V_{p d}=879.72\left(k / \phi^{3}\right)^{0.1388}$ & 0.873 & $V_{p d}=760.06\left(k / \phi^{3}\right) 0.1228$ & 0.868 \\
8 & $V_{p d}=973.59\left(k / \phi^{3}\right)^{0.1527}$ & 0.923 & $V_{p d}=793.1\left(k / \phi^{3}\right)^{0.135}$ & 0.927 \\
9 & $V_{p d}=1026.2\left(k / \phi^{3}\right)^{0.1713}$ & 0.973 & $V_{p d}=848.24\left(k / \phi^{3}\right)^{0.1485}$ & 0.961 \\
10 & $V_{p d}=1120.2\left(k / \phi^{3}\right)^{0.1902}$ & 0.968 & $V_{p d}=908.29\left(k / \phi^{3}\right)^{0.1585}$ & 0.953 \\
11 & $V_{p d}=1290.6\left(k / \phi^{3}\right)^{0.2117}$ & 0.979 & $V_{p} d=955.9\left(k / \phi^{3}\right)^{0.1627}$ & 0.983 \\
12 & $V_{p d}=1213.4\left(k / \phi^{3}\right)^{0.2077}$ & 0.970 & $V_{p d}=1025.3\left(k / \phi^{3}\right)^{0.1723}$ & 0.966 \\
13 & $V_{p d}=1186\left(k / \phi^{3}\right)^{0.1987}$ & 0.982 & $V_{p d}=991.95\left(k / \phi^{3}\right)^{0.1766}$ & 0.953 \\
14 & $V_{p d}=1210.3\left(k / \phi^{3}\right)^{0.1948}$ & 0.957 & $V_{p d}=1038.7\left(k / \phi^{3}\right)^{0.1774}$ & 0.966 \\
15 & - & - & $V_{p d}=1156.9\left(k / \phi^{3}\right)^{0.2012}$ & 0.999 \\
\hline
\end{tabular}
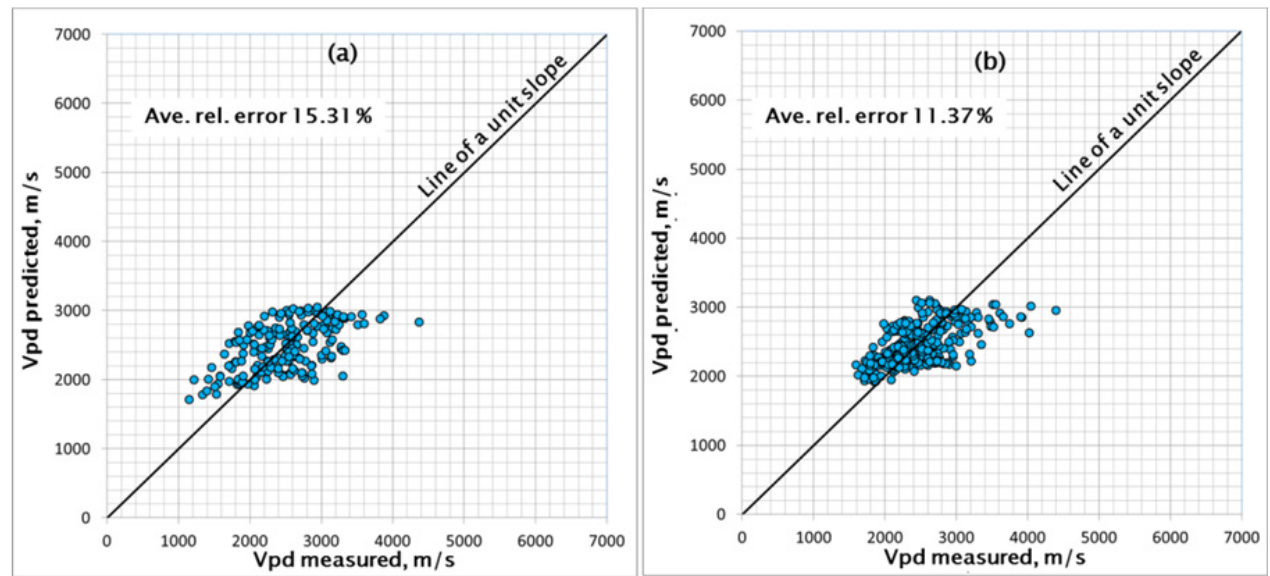

Figure A-1. Predicted versus measured $V_{p d}$ based on $(k / \phi)^{0.5}$ for ungrouped samples data set $1(\mathbf{a})$ and data $\quad$ set 2 (b)
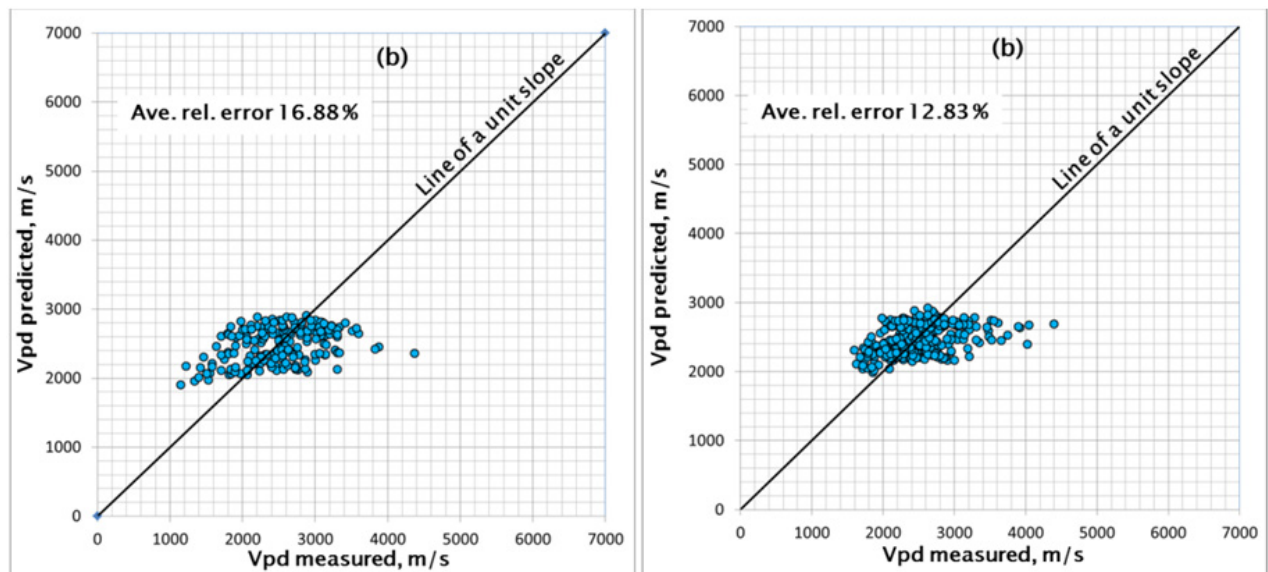

Figure A-2. Predicted versus measured $V_{p d}$ based on $\left(k / \phi^{3}\right)$ for ungrouped samples data set $1(\mathbf{a})$ and data $\quad$ set 2

(b)

\section{Copyrights}

Copyright for this article is retained by the author(s), with first publication rights granted to the journal.

This is an open-access article distributed under the terms and conditions of the Creative Commons Attribution license (http://creativecommons.org/licenses/by/3.0/). 